\title{
A TRADUÇÃO INTRALINGUAL E O DITIRAMBO: A QUESTÃO DOS GÊNEROS LITERÁRIOS NA REPÚBLICA DE PLATÃO
}

RESUMO:

Discorremos sobre um problema de tradução que está no centro da questão da teoria e da historia dos gêneros literários na República de Platão, no passo onde Sócrates exemplifica o que seja a narrativa pura. Pretendemos, desse modo, ressaltar alguns aspectos ligados à teoria literária, a fim de problematizar as classificações e os esquemas apresentados no diálogo.

\section{PALAVRAS-CHAVE: Platão, ditirambo, teoria literāria, gêneros} literários, mímesis.

Ao discutir o tipo de poesia adequado para a educação dos guardiões da cidade, Sócrates passa a examinar o último aspecto do lógos, que é a léxis. No correr dos livros II e III, já foram examinados os gêneros (eídea) do lógos, as coisas que devem ser ditas (hà lektéon), e agora resta examinar o modo como se deve dizer (hos lektéon). ${ }^{1}$ A léxis, bem entendido, é o ato de falar, a maneira de falar, o estilo, a elocução, a expressão, a dicção. ${ }^{2}$

Socrates começa então definindo o que dizem os mitólogos e poetas:

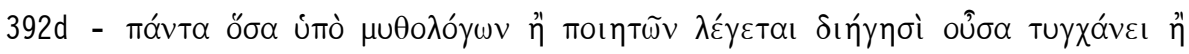

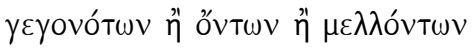

tudo quanto é dito pelos prosadores ou poetas é uma narrativa de acontecimentos passados, presentes ou futuros. ${ }^{3}$

A diégesis, mais comumente traduzida por 'narrativa', seria a ação de expor em detalhe, narrar, descrever. Após aquela definição, são caracterizados os tipos de narrativa:

* Mestre em Letras: Estudos Literários (Área de concentração: Teoria da Literatura), 2000. 


\section{EM TESE}

Belo Horizonte, v. 5, p. I-305, dez. 2002

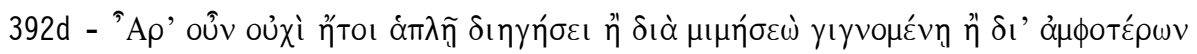

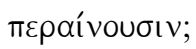

Porventura eles não a executam por meio de simples narrativa, através da mimese, ou por meio de ambas?

Sócrates exemplifica os tipos de narrativa utilizando como exemplo o começo da Ilíada (I, 12-42), quando o sacerdote Crises implora a Agamêmnon que the solte a filha. À princípio, o fator analisado diz respeito à situação de enunciação propriamente dita. A narrativa pura (haplè diégesis) ocorre quando o próprio poeta fala. A mímesis ocorre quando o poeta tenta voltar nosso pensamento para outro lado, como se fosse outra pessoa que dissesse, e não ele, ${ }^{4}$ assemelhando na voz e na aparência sua léxis à da pessoa cuja fala anunciou. Por exemplo, o texto em questão comporta ambos os tipos de narrativa, pois Homero inicia em terceira pessoa, narrando como ele próprio, e logo passa ao discurso em primeira pessoa, mimetizando o sacerdote. A alternância entre blocos miméticos e diegéticos é bastante simétrica nesses versos da Ilíada, (5 dieg. +4 mim. +7 dieg. +4 mim. +6 dieg.), pois as falas do poeta são intercaladas entre os discursos dos personagens.

Platão pretende demonstrar a possibilidade de reescritura de um passo diegético-mimético em forma puramente diegética. Trata-se, como afirma Montanari, de traduzir Homero do grego para o grego (Mnontanari. Apud Spina, 1994: 173). Sócrates simula uma versão simples (haplé) desse mesmo trecho da Ilíada, através de uma paráfrase. ${ }^{5}$

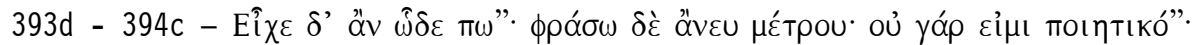

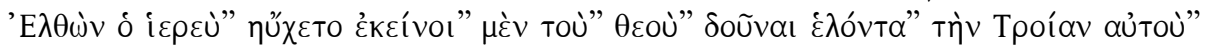

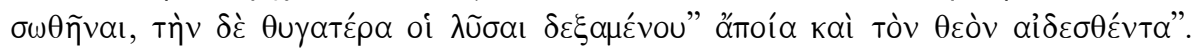

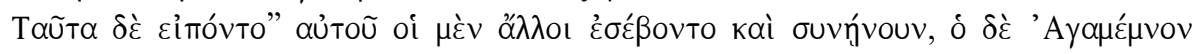

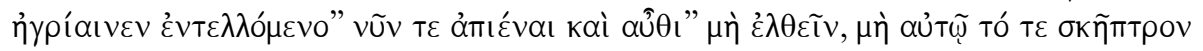

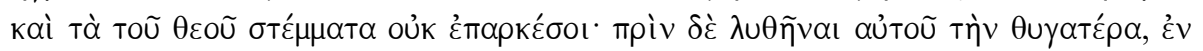

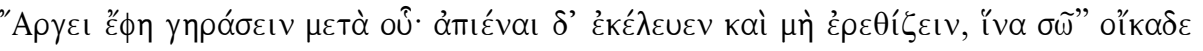

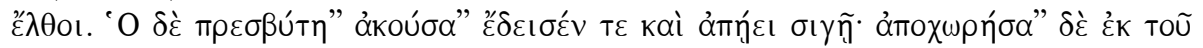

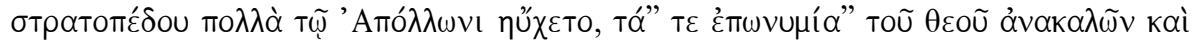

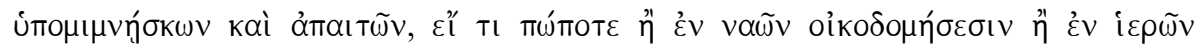

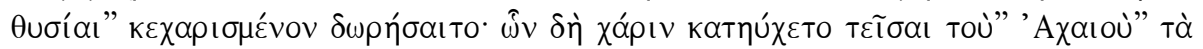

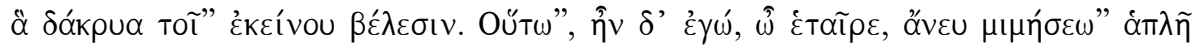

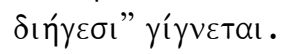

Seria mais ou menos assim (exprimo-me sem metro porque não sou poeta): 0 sacerdote chegou e fez votos por que os deuses thes concedessem conquistar Tróia e salvar-se, mas que the libertassem a filha mediante resgate, por temor aos deuses. A estas palavras, os outros respeitaram-no, e concordaram; 
porém Agamêmnon, enfurecido, ordenou-1he que se retirasse imediatamente e não voltasse, sob pena de de nada lhe valerem o ceptro e as bandas do deus. Antes de libertar a filha, havia de envelhecer em Argos, junto dele. E mandou-The que se retirasse, e não o excitasse, a fim de que pudesse regressar a casa a salvo. 0 ancião, ao ouvir estas palavras, teve receio e partiu em silêncio, e, afastando-se do acampamento, dirigiu muitas preces a Apolo, invocando os atributos do deus, recordando e pedindo retribuição, se jamais, ou construindo templos, ou sacrificando vitimas, The tinha feito oferendas do seu agrado. Como retribuição, pedia que os Aqueus pagassem as suas lágrimas com os dardos do deus. É assim, ó companheiro, que se faz uma narrativa simples sem imitação - conclui eu.

A narrativa é feita em terceira pessoa, incluindo os trechos miméticos, que são as duas falas do sacerdote e a fala de Agamêmnon. Sócrates adverte que a fará sem metro (áneu métrou), pois não é poeta. 0 resultado parece de fato prescindir de muitas das características próprias da poesia. A começar, pela ausência dos epítetos e gentílicos, tradicionais na poesia grega; a simplicidade da prosa, em contraposição à elevação do estilo homérico; a escassez de adjetivos; a objetividade do relato, que se detém apenas nos fatos principais; a falta de caracterização e descrição dos personagens, bem como dos espaços onde ocorrem as ações; ausência de vocativos e de invocações, o que é muito marcante se levarmos em conta que os primeiros versos da Ilíada iniciam com uma invocação à Musa, que não é incluída na paráfrase. É ainda importante observarmos que o trecho, apesar de ilustrar a narrativa pura, supõe vários níveis de mímesis: Platão, que mimetiza Sócrates, que mimetiza (ou, se quisermos, traduz) Homero.

Tudo isso levanta o seguinte problema: existiria de fato uma narrativa simples (ou pura) e poética? Se esta divisão refere-se exclusivamente à situação de enunciação poética, como afirma Genette (Genette In: Garrido, 1988: 191), por que Platão não citou algum outro gênero como exemplo da narrativa pura ou mesmo um outro trecho qualquer de Homero? Qual a necessidade de utilizar a tradução intralingual? Note-se ainda a imprecisão com que o trecho é introduzido, através de um imperferto mais a partícula ân, ${ }^{6}$ acrescidos ainda do advérbio pós. ${ }^{7}$ Essa questão se complica ainda mais quando Sócrates relaciona os tipos de narrativa que definiu com alguns dos gêneros empíricos da poesia grega: 


\section{EM TESE}

Belo Horizonte, v. 5, p. I-305, dez. 2002

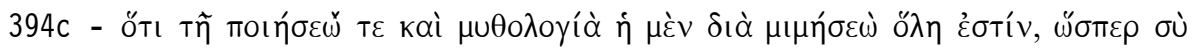

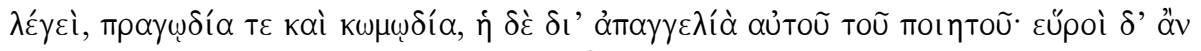

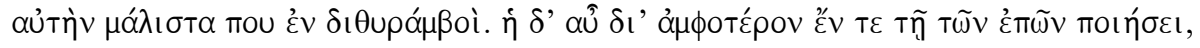

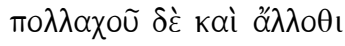

Em poesia e em prosa há uma léxis que é toda mimese, como tu dizes, a tragédia e a comédia; outra, narração do próprio poeta - podemos encontrála em algum lugar nos ditirambos; e outra ainda constituída por ambas, que se usa na composiçãa da epopéia e em muitos outros e diferentes lugares.

No caso da mímesis, basta retirarmos do texto de Homero as partes em que o próprio poeta fala e restarão apenas as falas dos personagens, tal como acontece na tragédia e na comédia. A narrativa pura (haplè diégesis) se dá através da narração (apangelía) do próprio poeta, e seu exemplo é o ditirambo. A narrativa mista, como exemplificada acima, encontra-se na epopéia e em muitos outros lugares. Note-se a grande importância atribuída a Homero, que parece ser a base da dedução dos outros dois tipos de narrativa.

\begin{tabular}{|c|c|c|}
\hline narrativa pura & narrativa mista & narrativa mimética \\
\hline $\begin{array}{c}\text { Versão haplé do começo } \\
\text { da Ilíada }\end{array}$ & Começo da Ilíada & $\begin{array}{c}\text { Diálogos da Ilíada, } \\
\text { sem as falas do poeta }\end{array}$ \\
\hline $\begin{array}{c}\text { Em algum lugar } \\
\text { nos ditirambos }\end{array}$ & $\begin{array}{c}\text { Na epopéia e em muitos } \\
\text { outros e diferentes lugares }\end{array}$ & Tragédia e comédia \\
\hline
\end{tabular}

Quadro 1 - Tipos de narrativa

A expressão málista pou en dithyrambois foi traduzida por Pereira por "de preferência, nos ditirambos". Contudo, ela contém a imprecisão do advérbio indeterminado $(p o u ́)^{8}$, que não deve ser desprezada, podendo também ser traduzida por "mais ou menos nos ditirambos", ou ainda "em algum lugar nos ditirambos". A imprecisão é acentuada ainda pelo uso do optativo heurois mais a partícula án. ${ }^{9}$ Notemos que, enquanto os gêneros épico e dramático estão bem definidos (Quadro 1), o mesmo não acontece com a narrativa simples, aqui representada pelo ditirambo, gênero obscuro, de difícil definição. 0 que seja de fato essa narrativa pura não fica claro para nós, pois, dos exemplos dados, um é forjado (a versão haplé da Ilíada) e o outro por demais obscuro (o ditirambo). Além do mais, o aspecto narrativo não é um dos principais elementos do gênero lírico, que poderia talvez estar pressuposto na classificação da narrativa pura. 
A mais famosa divisão que perdura com força até os nossos dias é aquela que divide os gêneros literários em três grandes grupos: o lírico, o épico e o dramático. ${ }^{10}$ Segundo Genette, tal divisão é atribuida já há algum tempo a Platão e a Aristóteles, tendo raízes profundas em nossa consciência ou inconsciência literária. ${ }^{11}$ Esse esquema está na base de toda a teoria dos gêneros desenvolvida no Ocidente, ainda que adaptada e reformulada. Contudo, não podemos afirmar que este modelo - a narrativa pura - corresponda de fato ao gênero lírico, pois não há elementos suficientes para tal.

De qualquer maneira, Platão está enfatizando aqui o caráter narrativo e não-mimético do ditirambo. Essas características parecem não estar supostas nos outros diálogos em que se faz referência ao gênero. ${ }^{12}$ Interessa-nos, contudo, observar que, nas Leis, encontramos uma espécie de história dos gêneros poéticos, que considera o ditirambo uma forma poética antiga, da qual teria derivado o teatro.

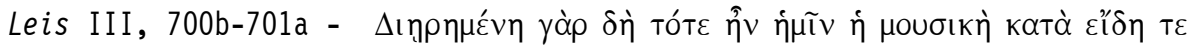

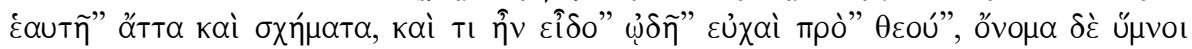

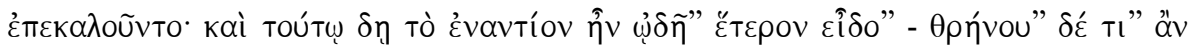

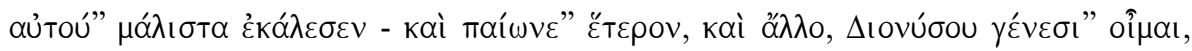

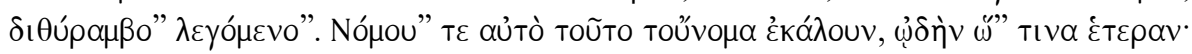

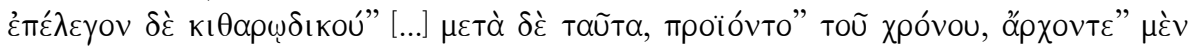

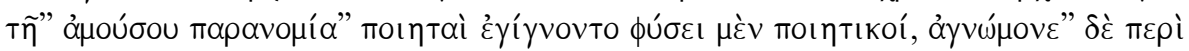

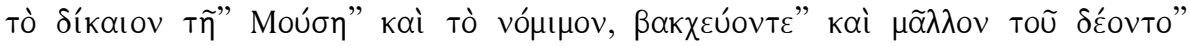

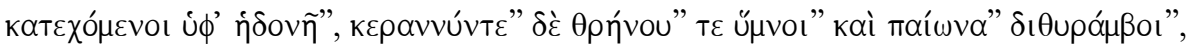

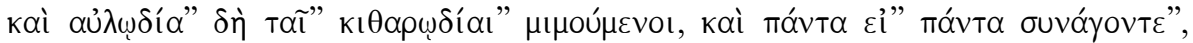

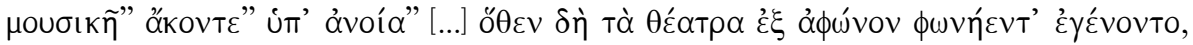

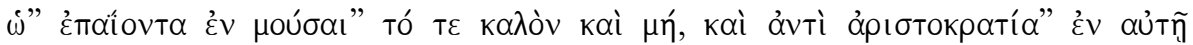

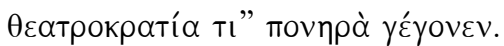

Naquele tempo, a música para nós era dividida em gêneros e modos definidos. Havia cantos que se chamavam hinos, sob a forma de preces dirigidas aos deuses; em oposição a esses, tínhamos a modalidade denominada treno, e mais os peãs e também os chamados ditirambos, porque celebravam, me parece, 0 nascimento de Dioniso. Dava-se precisamente o nome de leis, ou nomos, a uma outra espécie de ditirambo, com a designação genérica de citarédica. (...) Com o correr do tempo, assumiram os poetas o papel de juízes nas transgressões das regras musicais, todos eles, sem dúvida, naturalmente bem dotados, porém jejunos da justiça e do direito das Musas; tomados pelo frenesi bacântico mais do que fora admissivel e atolados nos prazeres, misturaram trenos com hinos, peãs com ditirambos, imitaram a flauta na cítara e reduziram tudo a tudo, caluniando inconscientemente a música, por pura ignorância (...) Como conseqüencia disso, os teatros, até então mudos, levantaram a voz, como se conhecessem 0 que é belo ou feio em matéria de música, passando a ocupar o lugar da aristocracia a pior teatrocracia. (trad. de Carlos Alberto Nunes) 


\section{EM TESE}

Belo Horizonte, v. 5, p. I-305, dez. 2002

Poderíamos supor que o tipo intermediário de poesia, cuja característica é a mistura de vários gêneros poéticos, equivaleria ao que se encontra em Homero e em outros poetas. No livro X da República, Sócrates afirma ser Homero o primeiro dos tragediógrafos, o que indica que considera o teatro uma derivação da epopéia. Confrontando a "história" das Leis com os modelos presentes na República, somos levados a pensar que:

1. 0 ditirambo poderia representar, na concepção de Platão, um estágio inicial da poesia antiga, sendo um gênero puro e sem mistura. Estaria agrupado junto à hímnica, aos trenos e aos nomos. Seu aspecto divino e inspirado poderia fazer dele um exemplo do lógos simples e verdadeiro, e também da poesia inspirada. Note-se que, na primeira cidade, os habitantes cantam hinos aos deuses (Rep. 372b).

2. Homero e outros poetas representariam uma forma poética intermediária, mista, derivada dos hinos e ditirambos. Sua principal característica é a variedade e o excesso, cultivados por ignorância. Prima por misturar a narrativa pura e a mimética, e por mesclar características diversas.

3. 0 teatro, mais propriamente a tragédia, derivaria de Homero. Não tendo nada em comum com o modo de representação do ditirambo, ele representa o lógos mimético, seu extremo oposto.

Podemos levar ainda em consideração o testemunho de Aristóteles, na Poética, que afirma a tragédia ser derivada do ditirambo. Com efeito, Aristóteles caracteriza a tragédia, em sua fase inicial, como nascida de um princípio improvisado; de elocução grotesca (léxis géloia) e satírica; mais afim à dança, o que incluía uma grande importância do coro; e, por fim, como gênero monológico. Fala ainda da substituição do tetrâmetro trocaico pelo trímetro jâmbico, metro mais adequado para o diálogo, por aproximar-se mais da fala cotidiana. Entretanto, apesar do testemunho de Aristóteles, que confirma em parte o de Platão, não se pode afirmar que 0 ditirambo carecesse de mímesis:

por mais que o ditirambo narrativo não mimético de caráter literário tenha ocupado o lugar de honra no séc. $V$, é bem claro que diversos rituais religiosos, mais os textos de Arquíloco, Eurípedes e Aristófanes, faziam 
bem conhecida a existência de um ditirambo plenamente dionisíaco, de caráter dialogado e mimético (...). E existiam logo entre ambos influências que se entrecruzavam. (Adrados, 1983: 49)

0 certo é que, seja como for o ditirambo, Platão e Aristóteles enfatizaram seu caráter narrativo em detrimento do mimético. Contudo, pela imprecisão com que o ditirambo é apresentado na República, tendemos a formular algumas hipóteses: ou Platão está-se referindo simplesmente ao tipo de situação de enunciação, e foi infeliz na escolha do exemplo, pois poderia ter citado qualquer outro gênero (hinos, peãs, leis, nomos, etc.); ou Platão está se referindo àquele lógos simples e verdadeiro (haplós kaì alethés), o lógos divino, que não encontra paralelo nos gêneros empíricos da poética grega. De acordo com esta segunda hipótese, a narrativa pura não diz respeito apenas à enunciação poética, mas à natureza mesma do lógos, que confunde forma e conteúdo. Se aceitarmos esta última hipótese, a narrativa pura nada mais é que um gênero teórico, e o ditirambo um gênero muito antigo e propício às mais variadas idealizações. Nesse caso, ele representaria o princípio (arkhé) da narrativa, tanto em seu aspecto histórico, tanto em seu aspecto ontológico. Uma interpretação extrema para a utilização do ditirambo como exemplo da narrativa simples seria, ainda, entendermos isso como uma ironia, pois pode parecer demasiado absurdo que logo o hino a Dioniso, deus do teatro, venha a ser o exemplo da poesia não-mimética.

NOTAS

1. Cf. Rep. 392c.

2. Havelock salienta que, à medida que a argumentação avança, a léxis passa a abarcar a estrutura verbal, rítmica e figurativa do poeta. (Cf. Havelock, 1996: 37)

3. As traduções da República aqui apresentadas são de autoria de Maria Helena da Rocha Pereira, com algumas modificações.

4. Cf. Rep. 393a.

5. Note-se ainda que nos passos 392e e 393d, enquanto Sócrates explica os critérios de definição da narrativa pura e da narrativa mimética, ocorrem também duas paráfrases do mesmo trecho da Ilíada em narrativa pura, só que de maneira muito sintética (Cf. Montanari. Apud Spina, op. cit: 173 passim).

6. A particula án mais o verbo no imperfeito apresenta uma ação como não realizada, como irreal. 


\section{EM TESE}

Belo Horizonte, v. 5, p. I-305, dez. 2002

7. 0 advérbio pós significa de qualquer maneira, de qualquer modo, etc., com um sentido predominante de atenuação.

8. 0 advérbio indefinido poú pode significar em alguma parte, de qualquer maneira, talvez, provavelmente, por acaso; com o sentido sempre marcado pela indeterminação.

9. 0 uso do optativo mais a partícula án, caracteriza uma frase do tipo potencial (possibilidade desejada)

10. A tripartição genérica em lírica, épica e drama parece ser sugerida em alguns passos (cf. Rep. 379a, 607a). Como veremos, a narrativa pura parece não estar se referindo à lírica, mesmo porque ao tratar do mélos, no passo 398d, Sócrates sugere uma grande divisão entre poesia cantada, que seria a lírica, e poesia não cantada, que seria a épica e o drama. Segundo ele, devem-se aplicar os mesmos modelos, utilizados na análise da épica e do drama, na lírica. Nesse sentido, deve-se pensar que também a poesia cantada divide-se em narrativa pura, narrativa mimética e narrativa mista.

11. Genette acredita que essa divisão tradicional dos gêneros remonta, de fato, ao romantismo (Cf. Genette. In: Garrido, op. cit.: 183-184).

12. Cf. Hippias Maior (292c), Hippias Menor (368d), Íon (534c), Crátilo (409b), Fedro (238d, 241e), Górgias (501e, 502a), Apologia (22b) e Leis III (700b).

13. Nos passos $595 \mathrm{c}$ e 607 a Homero é considerado o primeiro dos tragediógrafos, o que faz com que algumas vezes ele seja julgado juntamente com a tragédia. No passo 598d, Homero é chamado de corifeu da tragédia.

14. Cf. ARISTÓteles. Poética, 1449a.

ABSTRACT :

The aim of this article is to discourse upon a problem of translation which is a central question to the theory and history of literary genres in Plato's Republic, in the passage in which Socrates exemplifies the meaning of the pure narrative. Thus, the intention is to bring out some aspects concerning the literary theory, in order to question the classification and schemes presented in that dialog.

KEY WORDS: Plato, dithyramb, literary theory, literaray genres, mimesis. 
ADRADOS, Francisco Rodríguez. Fiesta, comedia e tragedia. Madrid: Alianza Editorial, 1983.

GENeTTE, G. Géneros, "tipos", modos. In: GARRIDO Gallardo, M. A. Teoria de los géneros literarios. Madrid: Arco, 1988, p. 183-233.

HAVELOCK, Eric. Prefácio a Platão. Trad. Enid Abreu Dobránzsky. Campinas: Papirus, 1996.

HESÍODO. Os trabalhos e os dias. Trad., introdução e comentários de Mary de Camargos Neves Lafer. São Paulo: Iluminuras, 1991.

- Teogonia. A origem dos deuses. Edição revisada e acrescida do original grego. Estudo e trad. de Jaa Torrano. São Paulo: Iluminuras, 1991.

HOMERO. Ilíada. Trad. em versos de Carlos Alberto Nunes. São Paulo: Ediouro, [19??].

LAGE, Celina F. Teoria e crítica literária na República de Platão. 2000. Dissertação (Mestrado em Teoria da Literatura) - Faculdade de Letras/UFMG, Belo Horizonte.

PLATÃo. Diálogos. Leis e Epinomis. Trad. Carlos Alberto Nunes. Belém: UFPA, 1980.

- República. Introdução, trad. e notas de Maria Helena da Rocha Pereira. Lisboa: Fundação Calouste Gulbenkian, 1990.

PLATON. La République. Texte établi et traduit par Emile Chambry. 3 vol. Paris: Les Belles Lettres, 1947.

SPINA, Luigi. Platone 'traduttore' di Omero. In: Eikasmos. v. V, p.173-179, 1994. 